\title{
ВЛИЯНИЕ МЕРОПРИЯТИЙ ПО ПОВЫШЕНИЮ ЭНЕРГОЭФФЕКТИВНОСТИ НА ЭКОНОМИЧЕСКИЕ ПОКАЗАТЕЛИ ПРЕДПРИЯТИЯ
}

\author{
(ㄷ) 2021 Язев Ярослав Вячеславович \\ студент-магистр \\ Университет ИТМО, Россия, Санкт-Петербург \\ E-mail: yaroslav.v.yazev@gmail.com \\ (c) 2021 Павлюков Александр Викторович \\ студент-магистр \\ Университет ИТМО, Россия, Санкт-Петербург \\ E-mail: off.mail.pavlyukov.a.v@gmail.com \\ (c) 2021 Пашинцева Виктория Сергеевна \\ студент-магистр \\ Университет ИТМО, Россия, Санкт-Петербург \\ E-mail: victoria.polukhina@mail.ru
(c) 2021 Хэлльстром Анастасия Константиновна
студент-магистр
Университет ИТМО, Россия, Санкт-Петербург
E-mail: nastya_zem@mail.ru
(c) 2021 Хэлльстром Денис Александрович
студент-магистр
Университет ИТМО, Россия, Санкт-Петербург
E-mail: dion.hellstrom@yandex.ru

Научная статья посвящена проведению исследовательского анализа особенностей воздействия мероприятий по повышению энергоэффективности предприятия на экономические показатели его коммерческой деятельности. Актуальность исследования обусловлена тем, что в условиях кризиса все большее число предприятий экономики России принимают решения по управлению энергоэффективностью, оценка результативности которого отражает влияние на финансовое состояние бизнеса. В рамках статьи рассмотрены теоретические аспекты понятия «управление энергоэффективностью». Проанализированы основные мероприятия, которые предприятия применяют в рамках повышения своей энергоэффективности. Проведена оценка влияния мероприятий по повышению энергоэффективности на экономические показатели коммерческих организаций.

Ключевые слова: управление энергоэффективностью; энергоэффективность; повышение энергоэффективность; экономические показатели; экономическая эффективность; энергетические затраты.

Система управления энергоэффективностью является одним из ключевых направлений совершенствования производственной деятельности предприятий современной экономики Российской Федерации. В первую очередь, данный процесс связан с тенденцией принятия решения об использовании методов и механизмов энергосбережения, путем применения инновационных технологий и моделей.

Актуальность научного исследования на тематику «влияние мероприятий по повышению энергоэффективности на экономические показатели предприятия» обусловлена тем, что в условиях кризиса все большее число предпри- ятий экономики России принимают решения по управлению энергоэффективностью, оценка результативности которого отражает влияние на финансовое состояние бизнеса.

По этой причине, целью научной работы выступает проведение исследовательского анализа особенностей воздействия мероприятий по повышению энергоэффективности предприятия на экономические показатели его коммерческой деятельности.

Эффективность использования энергии, или повышение энергоэффективности означает такое состояние системы (использование энергетических ресурсов), при котором энергопотре- 
бление сводится к минимально возможному уровню для производства продукции без снижения ее качества. Энергоэффективность опирается, как правило, на оптимизацию потребления, которая, в свою очередь, достигается путем нахождения менее энергоемких затрат [4].

Управление энергоэффективностью состоит из нескольких этапов, каждый из которых ответственен за свои задачи:

1. Проведение энергетического аудита и заполнение формы оперативного учета.

2. Ежегодная самооценка состояния энергетического менеджмента предприятия.

3. Выявление слабых сторон энергетического менеджмента предприятия и определение направлений его развития.

4. Формирование перечная мероприятий по повышению энергоэффективности.

5. Принятие управленческих решений о повышении энергоэффективности предприятия.

6. Реализация мероприятий по повышению энергоэффективности предприятия.

7. Экономическая оценка, расчет и распределение экономии от мероприятий повышения энергоэффективности.

На сегодняшний день, предприятия российской экономики применяют следующие мероприятия, которые направлены на повышение энергоэффективности [1; 2]:

1. Обновление производственного и офисного оборудования. Например, использование новых персональных компьютеров для офисных сотрудников позволяет в разы сократить потребление электроэнергии.

2. Снижение размера энергоемкости производства продукции или предоставления услуги. В частности, это возможно благодаря тому же обновлению производственного оборудования или при применении новых зеленых технологий.

3. Снижение уровня загрязнения окружающей среды, поскольку для промышленных предприятий это означает, в первую очередь, уменьшение размера уплаты экологического налога за выбросы СО2 в атмосферу.

4. Увеличение эффективности использования электроэнергии в системах электроснабжения и электроприемников.

5. Регулирования режимов работы технологического и производственного оборудования.

6. Улучшение качества электроэнергии.

7. Применение возобновляемых источников энергии при подаче электроэнергии и ее использовании в производственных целях.

В топливно-энергетическом балансе многих стран мира как развитых, так и развивающихся возобновляемые источники энергии (ВИЭ) уже играют немаловажную роль. Некоторые страны уже сейчас разрабатывают планы полного или почти полного перехода на ВИЭ.

На рисунке 1 изображена динамика производства альтернативной энергетики в России.

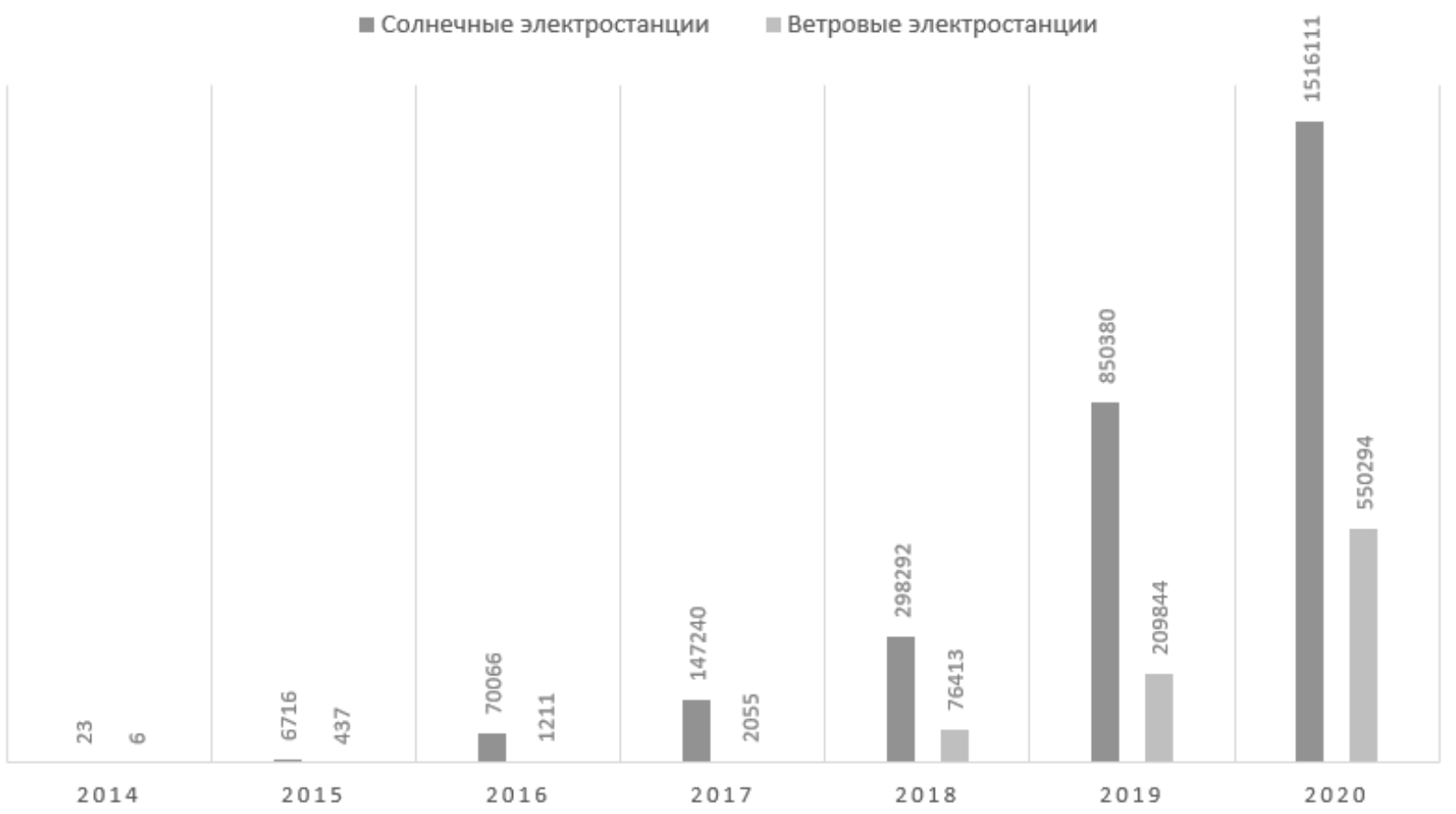

Puc. 1. Динамика объема выработки электроэнергии при помощи возобновляемых источников энергии (солнечные и ветровые электростанции) в России в период 2014-2020 гг., тысяч кВтч [3] 
Возобновляемые источники энергии в промышленном секторе российской экономики создают все больший акцент на зеленые технологии и на производство продукции с высокой добавленной стоимостью. Применение зеленых технологий ВИЭ способствует снижению производственных расходов предприятий из-за использования энергосберегающего оборудования, а эффективность и производительность труда, наоборот, повышаются.

Как нами было отмечено, последним этапом управления энергоэффективности предприятия является экономическая оценка, расчет и распределение экономии от мероприятий энергосбережения. Поэтому так важен анализ влияния данных механизмов на экономические показатели коммерческой организации.

Главным направлением воздействия мероприятий по повышению энергоэффективности на экономические показатели предприятия является экономия его финансовых ресурсов. Для оценки экономии финансовых ресурсов, необходимо проведение аудита и экономического анализа, включая динамику денежных потоков, выручки, прибыли компании, а также себестоимости продукции и рентабельности бизнеса. Это все позволит провести анализ влияния мероприятий по повышению энергоэффективности на экономические показатели предприятия.

В рамках процедуры экономической оценки и расчета влияния энергоэффективности на экономические показатели предприятия могут использоваться следующие инструменты, среди которых [5]:

- индекс выброса СO2;

- показатели энергоемкости производства продукции;

- показатели эффективности использования энергетических ресурсов;

- индекс повышения производительности при экономии энергетических ресурсов;

- показатели эффективности передачи энергии.

В связи с процессом по проведению энергосберегающих мероприятий, российским предприятиям удается в значительном объеме сокращать размер своих финансовых затрат на энергоносители и тем самым положительно влиять на финансово-экономические показате- ли своей хозяйствующей деятельности, повышая уровень рентабельности и прибыльности. В итоге, финансовая устойчивость, экономическая безопасность и конкурентоспособность бизнеса повышаются.

Однако экономическая эффективность применения управленческих решений по энергосбережению на предприятиях российской экономики не всегда может быть такой в виду влияния таких проблем, как [6]:

- отсутствие свободных финансовых ресурсов и внеоборотного капитала для проведения мероприятий по обновлению основных фондов или внедрению энергоэффективных технологий и инноваций;

- низкий уровень профессиональных компетенций и образованности в вопросах энергоэффективности у управляющих организаций и их подчиненных, занимающихся процессами управления энергетическими затратами;

- приоритетность капитальных вложений инвестиций и финансового капитала в проекты на повышение производительности труда и оборудования, чем на снижение энергетических расходов;

- существенные потери предприятия при транспортировке энергетических ресурсов.

Таким образом, подводя итоги научной работы, можно заключить, что российским предприятиям необходимо применение мероприятий по повышению энергоэффективности, что позволит в значительном объеме сокращать размер своих финансовых затрат на энергоносители и тем самым положительно влиять на финансово-экономические показатели своей хозяйствующей деятельности, повышая уровень рентабельности и прибыльности. В итоге, финансовая устойчивость, экономическая безопасность и конкурентоспособность бизнеса повышаются.

Общая государственная стратегия управления энергоэффективностью, где будут поставлены задачи по решению вышеперечисленных актуальных проблем, позволит в общем увеличить конкурентоспособность отечественного бизнеса, отраслей, рынков, и тем самым повысить инвестиционную привлекательность национальной экономики. 


\section{Библиографический список}

1. Иванова В. В. Энергосбережение как экономический ресурс // Экономика промышленности. - 2009. - № 3 (46).

2. Колесник Ю.Н. Автоматизированная система управления энергоэффективность для снижения энергозатрат и энергоемкости производства // Перспективы инновационного развития угольных регионов России.-2014.- С. 42-44.

3. Рынок электроэнергии и мощности. URL: https://www.np-sr.ru/ru/market/vie/index.htm (дата обращения: 28.08.2021).

4. Рейшахрит Е.И. Особенности управления энергоэффективностью на предприятиях нефтеперерабатывающей отрасли // Записки Горного института. 2016. № 219. С. 490-497.

5. Мещерякова Т. С. Организация управления энергозатратами на предприятии // Энергосбережение.-2015.№ 6.- С. 64-67.

6. Соловьева Ю.В., Черняев М.В. Энергоемкость экономики и энергоэффективность: проблемы и перспективы // ЭТАП. 2019. № 6. С. 118-130. 